\title{
HIGH-TEMPERATURE DEFORMATION AND DIFFUSION IN OXIDES*
}

\author{
J. L.. Routbort \\ Materials Science Division. \\ Argonne National Laboratory \\ Argonne, IL 60439-4838 \\ ANL. $/ C P-75064$ \\ DE92 019593
}

June 1992

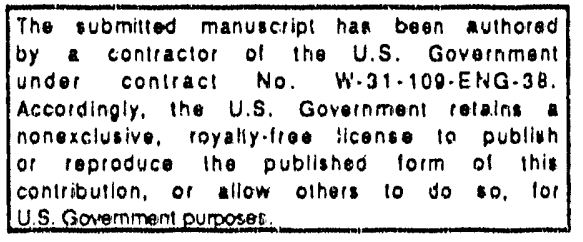

DISCLAIMER

\begin{abstract}
This report was prepared as an account of work sponsored by an agency of the United States Government. Neither the United States Government nor any agency thereof, nor any of their employees, makes any warranty, express or impilied, or assumes any legal liability or responsibility for the acruracy, completeness, or usefulness of any information, apparatus, producl, or process disclosed, or represents that its use would not infringe privalely owned rights. Teference herein to any specific commercial product, process, or service by trade name, trademark, manufacturer, or otherwise does not necessarily constitute or imply its endorsement, recom. mendation, or favoring by the United States Government or any agency thereaf. The views and opinions of authors expressed herein do not necessarily state or reflect those of the United States Government or any agency thereof.
\end{abstract}

INVTED PAPER to be presented at the 2nd Iketani Conference, International Conference on Diffusion in Materials, DIMAT-92, Kyoto, Japan, 7-11 September 1992, and published in the Proceedings as special volumes of Defects and Diffusion Forum, 'Trans Tech Fublications Ltd.

*Work supported by the U.S. Department of Energy, BES-Materials Sciences, under contract \#W-31-109-ENG-38. 


\section{HIGH-TEMPERATURE DEFORMATION AND DIFFUSION IN OXIDES}

J. L. Routbort

Materials Science Division

Argonne National Laboratory

Argonne, Il 60439-4838 USA

Topics: Deformation, Diffusion, Oxides

\section{ABSTRACT}

High-temperature, steady-state deformation is usually controlled by diffusion of the slowest moving ion along its fastest diffusion path. Therefore, measurements of steady-state deformation can, in principle, be used to obtain information concerning diffusion. This paper will briefly review the assumptions that relate creep, defect chemistry, and diffusion. Steady-state deformation of the $\mathrm{NaCl}$-structured oxides, $\mathrm{Co}_{1-\mathrm{x}} \mathrm{O}$ and $\mathrm{Mn}_{1-\mathrm{x}} \mathrm{O}$, and the perovskite-structured high-temperature superconductors $\mathrm{YBa}_{2} \mathrm{Cu}_{3} \mathrm{O}_{\mathrm{x}}$ and $\mathrm{Bi}_{2} \mathrm{Sr}_{2} \mathrm{CaCu}_{2} \mathrm{O}_{\mathrm{x}}$ will be discussed, emphasizing diffusion of the minority defects.

\section{INTRODUCTION}

The kinetics of high-temperature plasticity of metals and ceramics are commonly controlled by the nonconservative motion of dislocations, by pure transport of matter, or by grain boundary sliding, accommodated by matter transport. In general, most models can be described by a generalized creep equation:

$$
\dot{\varepsilon}=\mathrm{A}\left(\frac{b}{d}\right)^{h} \frac{\mu b}{\mathrm{kT}}\left(\frac{\sigma}{\mu}\right)^{n} D^{\text {eff }},
$$

where $\dot{\varepsilon}$ is the steady-state strain rate, $b$ the Burgers vector, $d$ the grain size, $\mu$ the shear modulus, $\sigma$ the stress, $D$ eff the effective diffusion coefficient, $\mathrm{A}$ a constant, and $\mathrm{kT}$ has its usual meaning. The grain size exponent, $h$, and the stress exponent, $n$, are deformation-model-dependent parameters; it is generally assurned that they are not functions of temperature or oxygen partial pressure, $\mathrm{P}_{\mathrm{O}_{2}}$. These assumptions must be verified if equation 1 is used to calculate $D^{\text {eff. }}$ 
Assuming that the deformation mechanism remains constant with stress or strain, the problem of how to relate Deff to the diffusion coefficients of the various species has recently been reviewed for binary [1] and ternary oxides [2]. The effective diffusion coefficient for the $x$ th species is given by:

$$
D_{x}^{e f f}=D_{x}^{l}+10\left(\frac{\sigma}{\mu}\right)^{2} D_{x}^{P}+\frac{\pi \delta}{d} D_{x}^{g b} .
$$

In equation 2 , superscripts refer to the lattice, $l$, dislocation core, $P$, and grain boundary, $g b$, paths. The grain boundary width is denoted by $\delta$. Consider an oxide, $\mathrm{A}_{\alpha} \mathrm{B}_{\beta} \mathrm{O}_{\gamma}$. Plastic deformation usually occurs without decomposition, so the fluxes, $J$, of the components must be in the same ratio as the components of the compound, therefore:

$$
\frac{J_{A}}{J_{B}}=\frac{\alpha}{\beta}, \quad \frac{J_{A}}{J_{O}}=\frac{\alpha}{\gamma}, \quad \frac{J_{B}}{J_{O}}=\frac{\beta}{\gamma} .
$$

Equation 3 can be rewritten for the combined diffusion coefficient, $D^{\text {eff }}$, in two different forms depending on whether it is assumed that the overall composition is constant [3]

$$
D_{c}^{e f f}=\left[\frac{\alpha}{D_{A}^{e f f}}+\frac{\beta}{D_{B}^{e f f}}+\frac{\gamma}{D_{O}^{e f f}}\right]^{-1}
$$

or whether the composition along each path is constant [3],

$$
D_{c}^{e f f}=\left[\frac{\alpha}{D_{A}^{l}}+\frac{\beta}{D_{B}^{l}}+\frac{\gamma}{D_{O}^{l}}\right]^{-1}+10\left(\frac{\sigma}{\mu}\right)^{2}\left[\frac{\alpha}{D_{A}^{P}}+\frac{\beta}{D_{B}^{P}}+\frac{\gamma}{D_{O}^{P}}\right]^{-1}+\frac{\pi \delta}{d}\left[\frac{\alpha}{D_{A}^{g b}}+\frac{\beta}{D_{B}^{g b}}+\frac{\gamma}{D_{O}^{g b}}\right]^{-1} .
$$

The forms of equations 4 and 5 are quite different and are only equal if the diffusion coefficient of one species is much smaller than the others, for any path.

In an oxide, the point defects are often associated with a deviation from stoichiometry. The thermodynamic equilibrium is fixed by the vapor pressures of the different components. In oxides, at high temperatures, $\mathrm{P}_{\mathrm{O}_{2}}$ and $\mathrm{T}$ usually control stoichiometry. In these cases,

$$
D_{c}^{e f f}=D_{o}\left(\frac{\mathrm{P}_{\mathrm{O}_{2}}}{\mathrm{P}_{\mathrm{O}_{2}}^{*}}\right)^{m} \exp \left(-\frac{\Delta H}{\mathrm{kT}}\right),
$$

where ${ }^{*}$ denotes the reference oxygen partial pressure, and $\Delta H$ is the activation energy for the diffusional process. If one species has a smaller diffusion coefficient, $m$ and $\Delta H$ are characteristic of that point defect, but if the diffusion coefficient of two of the species are about equal, the activation energy will be an average, but $m$ will still be characteristic of the point defects. Equation 6 is only valid for concentrations of 
defects sufficiently small so that they do not inieract. If defect-defect interactions have to be considered, the correlations between $m$ and $\Delta H$ are more complex. For example, non-ideality, at least in electrical conductivity, nonstoichiometry, and cation diffusion, becomes apparent in $\mathrm{C}_{01-\mathrm{x}} \mathrm{O}$ at $\mathrm{x} \geq 0.005$ [4].

\section{$\mathrm{Co}_{1 \cdot \mathrm{x}} \mathrm{O}$}

Cobalt monoxide is an ideal model oxide on which to test the relationship between deformation and diffusion. Pure single crystals of $\mathrm{C}_{1-\mathrm{x}} \mathrm{O}$ are available and the defect chemistry, for small $x$, is well known and easily controlled [5]. In addition, it is known that the diffusion of the anion is considerably slower than the diffusion of the cation [e.g. 6,7]. The high-temperature steady-state creep (constant load) of $\mathrm{Co}_{1-\mathrm{x}} \mathrm{O}$ single crystals has been investigated over a wide range of temperatures and $\mathrm{PO}_{2}$ [8]. In addition, the steady-state flow stress, $\tau_{s}$, in single crystals was investigated for nearly constant $\dot{\varepsilon}$ conditions [9]. Analysis of the deformation results, combined with TEM [10], indicates that deformation proceeds via dislocation climb and that steady state is achieved when the climb rate equals the recovery rate. Results obtained for the variation of $\tau_{\mathrm{s}}$ with $\mathrm{P}_{\mathrm{O}_{2}}$ at $1200^{\circ} \mathrm{C}$ and for $\dot{\varepsilon}=5 \times 10^{-5} \mathrm{~s}^{-1}$ are shown in Fig. 1 .

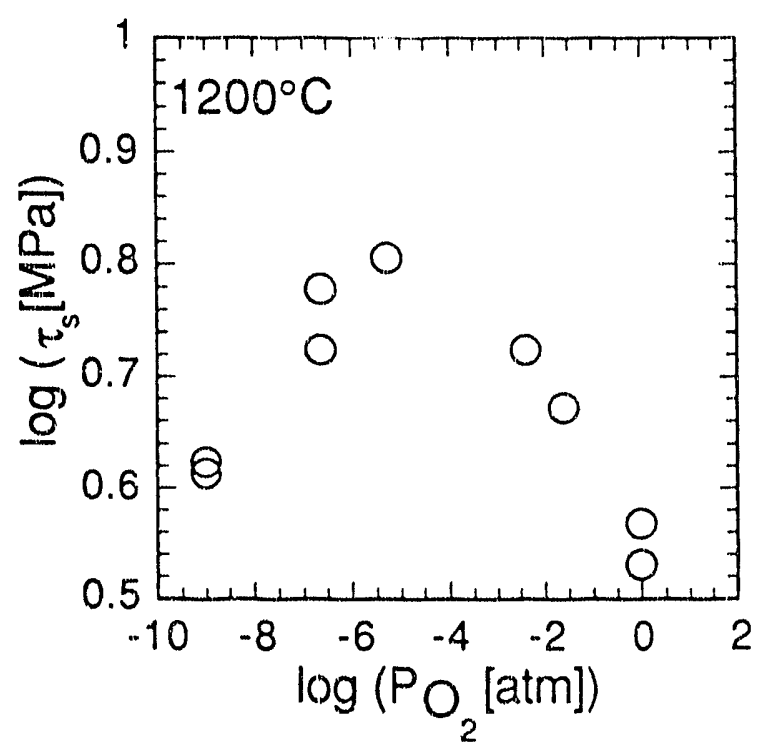

Fig. 1. Variation of $\tau_{\mathrm{s}}$ with $\mathrm{P}_{\mathrm{O}_{2}}$ for $\mathrm{CoO}$ at $1200^{\circ} \mathrm{C}$ and $\dot{\varepsilon}=5 \times 10^{-5} \mathrm{~s}^{-1}[9]$.

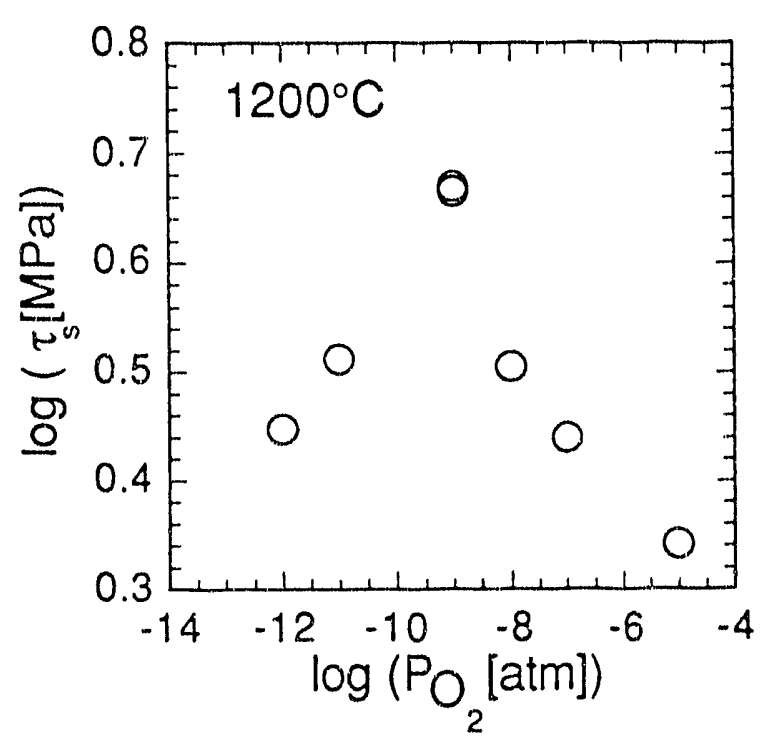

Fig. 2. Variation of $\tau_{\mathrm{s}}$ with $\mathrm{P}_{\mathrm{O}_{2}}$ for $\mathrm{MnO}$ at $1200^{\circ} \mathrm{C}$ and $\dot{\varepsilon}=5 \times 10^{-5} \mathrm{~s}^{-1}[13]$.

Data presented in figure 1 were taken from experiments performed at nearly constant strain rates and may be analyzed (values of $n$ were measured) to yield $m=1 / 5$ and $1 / 2$ for the low- and high- $\mathrm{P}_{\mathrm{O}_{2}}$ regions, respectively [9]. It should be noted that while $\tau_{\mathbf{s}}$ shows a maximum, creep and tracer diffusion measurements would show a minimum [9]. The $\mathrm{P}_{\mathrm{O}_{2}}$ dependence of $\tau_{\mathrm{S}}$, which is in agreement with measurements of constant-load creep [8], and the $\Delta H$ measurements are in full accord with the tracer diffusion measurements $[11,12]$. Therefore, identification of the rate-controlling species, oxygen vacancies and interstitials, for low- and high- $\mathrm{P}_{\mathrm{O}_{2}}$, respectively, is unambiguous and furthermore, the creep studies (at least as a function of $\mathrm{P}_{\mathrm{O}_{2}}$ ) preceded the diffusion measurements. 


\section{$\mathrm{Mn}_{1-\mathrm{x}} \mathrm{O}$}

The steady-state deformation of $\mathrm{Mn}_{1-\mathrm{x}} \mathrm{O}$ single crystals has been investigated over a wide range of $\mathrm{T}$ and $\mathrm{P}_{\mathrm{O}_{2}}[10,13,14]$. Analysis of creep results and TEM of the dislocation microstructure of deformed $\mathrm{MnO}$ established that the recovery process is one of dislocation climb. The similarity between $\tau_{\mathrm{s}}$ for $\mathrm{CoO}$ and $\mathrm{MnO}$ is striking and data for $\mathrm{MnO}$ are shown in figure 2. Oxygen tracer diffusion data are only available at 1 atm [15,16], but the activation energy for creep $(405 \pm 40 \mathrm{~kJ} / \mathrm{mole})$ and diffusion $(395 \pm 40 \mathrm{~kJ} / \mathrm{mole})$ agree at that point. Stress exponents were measured and used to calculate values of $m$ from plots similar to figure 2 . The conclusion was that for $\mathrm{T} \geq 1200^{\circ} \mathrm{C}$, volume diffusion dominates creep with singly charged oxygen vacancies and neutral oxygen interstitials controlling for low- and high- $\mathrm{P}_{\mathrm{O}_{2}}$, respectively. It appears that pipe diffusion becomes important for $\mathrm{T} \leq 1000^{\circ} \mathrm{C}$. The $\mathrm{C}^{2}$ ionization state of the minority defects decreases at $\mathrm{T} \approx 1400^{\circ} \mathrm{C}[13]$.

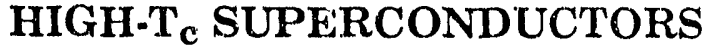

\section{$\mathrm{YBa}_{2} \mathrm{Cu}_{3} \mathrm{O}_{\mathrm{x}}$ and $\mathrm{Bi}_{2} \mathrm{Sr}_{1.7} \mathrm{CaCu}_{2} \mathrm{O}_{x}$}

Despite the intense interest in $\mathrm{YBa}_{2} \mathrm{Cu}_{3} \mathrm{O}_{\mathrm{x}}(\mathrm{YBCO})$, high-temperature, steady-state deformation studies on fully dense material have only been performed within a narrow $\mathrm{T}\left(850-980^{\circ} \mathrm{C}\right)$ and $\mathrm{P}_{\mathrm{O}_{2}}(0.01-1.0 \mathrm{~atm})$ range: deformation proceeds too slowly at lower temperatures and $\mathrm{YBCO}$ decomposes at high temperatures and low $\mathrm{P}_{\mathrm{O}_{2}}$. Nevertheless, creep studies have determined $n=1$, and $h=2.8[17,18]$. These values, combined with the microstructural observations that the grain shape remains constant during deformation, indicate that plasticity occurs by a grain boundary sliding accommodated by diffusion. Some results obtained under nearly constant strain rate conditions are shown in figure 3 [17]. The results are not as easily interpreted as results for the simple oxides discussed above. The activation energy for creep in YBCO is a function of $\mathrm{P}_{\mathrm{O}_{2}},(970 \pm 130 \mathrm{~kJ} / \mathrm{mole}$ between 0.1 and $1.0 \mathrm{~atm}$ and $\approx 650 \mathrm{~kJ} / \mathrm{mole}$ for $0.01 \mathrm{~atm}$ ) [18].

Tracer diffusion of $\mathrm{Cu}[19]$ and the A-site cations, $\mathrm{Y}$ and $\mathrm{Ba}$ [20], has been recently investigated. The results are presented in the Arrhenius plot of figure 4. Also shown are the diffusion coefficients of some rare earth elements. As expected, the cations move considerably slower than oxygen [21]. The activation energies and $\mathrm{P}_{\mathrm{O}_{2}}$ dependencies for tracer diffusion are given in table 1 . The slowest moving species is $Y$, as would be expected from recent atomic simulations of point defects in YBCO which indicate that formation energies of $\mathrm{Ba}$ and $\mathrm{Y}$ defects are extremely high [22]. These calculations indicate that $\Delta H$ for $\mathrm{Y}$ is larger than that of $\mathrm{Ba}$, as observed. The creep activation energy agrees with that for tracer diffusion of $Y$, and therefore, $Y$ is probably the rate-controlling species responsible for the diffusion necessary to accommodate grain boundary sliding. One puzzlement is that changes of $\mathrm{P}_{\mathrm{O}}$ do not affect the tracer diffusion of $\mathrm{Ba}$, and presumably, although not determined, $\mathrm{Y}$. It is likely, however, that the lower activation energy for creep determined for $\mathrm{P}_{\mathrm{O}_{2}}=0.01 \mathrm{~atm}$ may be the result of deformation mechanism changes, or that the nature or path of the rate-controlling defect changes.

The only creep study of a $\mathrm{Bi}$-based superconductor, $\mathrm{Bi}_{2} \mathrm{Sr}_{1.7} \mathrm{CaCu}_{2} \mathrm{O}_{\mathrm{x}}$ [23], despite being performed at fixed $\mathrm{P}_{\mathrm{O}_{2}}$, in a narrow $\mathrm{T}$ and $\sigma$-range, indicates that a diffusional flow region exists characterized by an activation energy of $990 \pm 190 \mathrm{~kJ} / \mathrm{mole}$. 


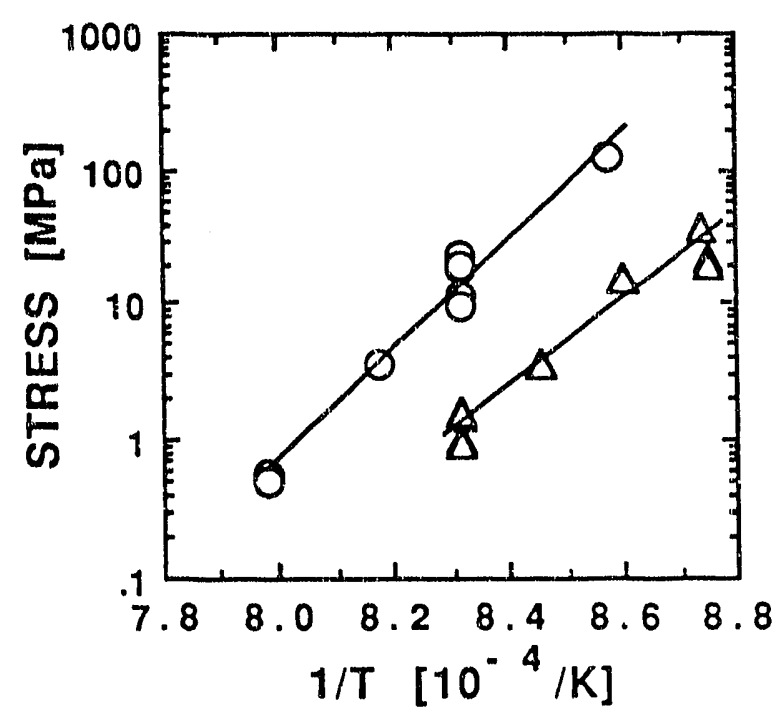

Fig. 3. Variation of the steady-state stress for YBCO with $1 / \mathrm{T}$ for $\dot{\varepsilon} \approx 1 \times 10^{-5} \mathrm{~s}^{-1}$ and $\mathrm{P}_{\mathrm{O}_{2}}=1$ (circles) and 0.01 atms (triangles) [17].

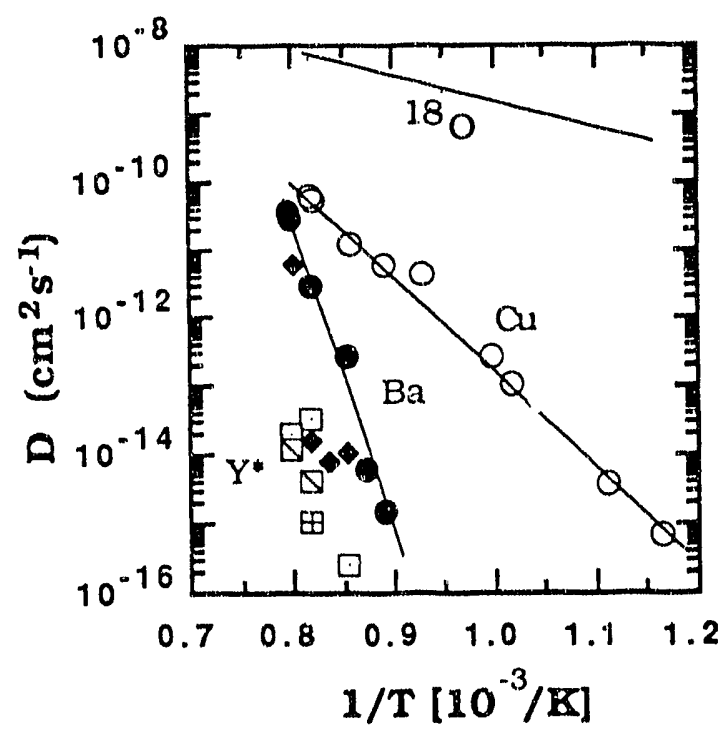

Fig. 4. Diffusion of $\mathrm{O}, \mathrm{Cu}, \mathrm{Ba}, \mathrm{Y}$, and rare earths in YBCO (filled diamonds = $Y$, squares with central dots $=D y$, squares with single diagonal $=\mathrm{Ho}$, and square with cross $=\mathrm{Gd}$ ) $[20]$.

Table 1. Activation energies and oxygen partial pressure dependencies for diffusion of $\cong$ mponents in bulk polycrystalline $\mathrm{YBa}_{2} \mathrm{Cu}_{3} \mathrm{O}_{\mathrm{x}}$.

\begin{tabular}{cccc}
\hline Tracer & $\begin{array}{c}\mathrm{Q} \\
(\mathrm{kJ} / \text { mole) }\end{array}$ & $\begin{array}{c}\mathrm{P}_{\mathrm{O}_{2}} \\
\text { Dependence }\end{array}$ & Reference \\
\hline $\mathrm{O}$ & $94 \pm 3$ & no effeci & 20 \\
$\mathrm{Cu}$ & $256 \pm 4$ & negative & 21 \\
$\mathrm{Ba}$ & $890 \pm 125$ & no effect & 19 \\
$\mathrm{Y}$ & $10^{3} \pm 200$ & unknown & 19 \\
\hline \hline
\end{tabular}

The activation energies for tracer diffusion of $\mathrm{O}$ along the $c$-axis, and for $\mathrm{Ag}$ in polycrystalline material, the only other cation measured, are 212 and $181 \mathrm{~kJ} / \mathrm{mole}$, respectively. It has been postulated that $\mathrm{Ca}$ is the rate-controlling species [23].

\section{CONCLUSIONS}

Careful measurements of high-temperature plasticity in oxides, when combined with examination of the deformed microstructures, can determine the charge states of the minority defect and the activation energy for diffusion. 


\section{Acknowledgments}

The author is grateful to all of his colleagues who participated in this work over the last decade. In particular, S.J. Rothman, K.C. Goretta, Nan Chen and .4. DomínquezRodríguez are acknowledged. This work was supported by the U.S. Department of Energy, Basic Energy Sciences-Materials Science, under Contract W-31-109-ENG-38.

\section{REFERENCES}

1. Domínguez-Rodríguez, A., Castaing, J., Goretta, K.C. and Routbort, J.L.: in Point Defects and Related Properties of Ceramics, edited by T.O. Mason and J.L. Routbort (American Ceramic Society, Westerville,OH, 1991), p. 139.

2. Domínguez-Rodríguez, A., Jiménez, M., Chen, Nan, Goretta, K.C., Rothman, S.J. and Routbort, J.L.: in press.

3. Jiménez, M., Domínguez-Rodríguez, A., Castaing, J. and Márquez, R.: Scripta Metall. 1986, 20, 839.

4. Constant, K., Mason, T.O. and Routbort, J.L.: J. Phys. Chem. Solids, 1992, 53, 413.

5. Dieckmann, R.:Z. Physik. Chem. Neue Folge, 1977, 107, 189.

6. Chen, W.K. and Peterson, N.L.: J. Phys. Chem. Solids, 1980, 41, 647.

7. Chen, W.K. and Jackson, R.A.: J. Phys. Chem. Solids, 1969, 30, 1309.

8. Domínguez-Rodríguez, A., Sánchez, M., Márquez, R., Castaing, J., Monty, C. and Philibert, J.: Phil. Mag., 1982, A46, 411.

9. Routbort, J.: Acta Metall., 1982, 30, 663.

10. Goretta, K.C., Cook, R.E. and Routbort, J.L.: J. Mater. Sci., 1986, 21, 4391.

11. Tarento, R.J.: Sol. State Ionics, 1988, 28-30, 1221.

12. Routbort, J.L. and Rothman, S.J.: J. Phys. Chem. Solids, 1986, 47, 993.

13. Goretta, K.C. and Routbort, J.L.: Acta Metall., 1987, 35, 1047.

14. Routbort, J.L., Castaing and J., Goretta, K.C.: J. Am. Ceram. Soc., 1986, 69, C114.

15. Yamaguchi, S. and Someno, M.: Trans. Jpn. Inst. Met., 1982, 23, 259.

16. Routbort, J.L. and Goretta, K.C.: in Nonstoichiometric Compounds, Advances in Ceramics, ed. C.R.A. Catlow and W.C. Mackrodt (Am. Ceram. Soc., Westerville, $\mathrm{OH}, 1987) 23,71$.

17. von Stumberg, A.W., Chen, N., Goretta, K.C. and Routbort, J.L.: J. Appl. Phys., $1989,66,2079$.

18. Goretta, K.C., Routbort, J.L., Biondo, A.C., Gao, Y., de Arellano-Lopez, A.R., and Dominguez-Rodríguez, A.: J. Mater. Res., 1990, 5, 2766.

19. Routbort, J.L., Rothman, S.J., Chen, N., Mundy, J.N. and Baker, J.E.: Phys. Rev. B, 1991, 43, 5489 .

20. Chen, N., Rothman, S.J., Routbort, J.L., and Goretta, K.C.: J. M iter. Res., in press.

21. Rothman, S.J., Routbort, J.L. and Baker, J.E.: Phys. Rev. B, 1989, 40, 8852.

22. Baetzold, R.C.: private communication, 1992.

23. Routbort, J.L., Goretta, K.C., Miller, D.J., Kazelas, D.B., Clauss, C., and Domínguez-Rodríguez, A.: J. Mater. Res., in press. 

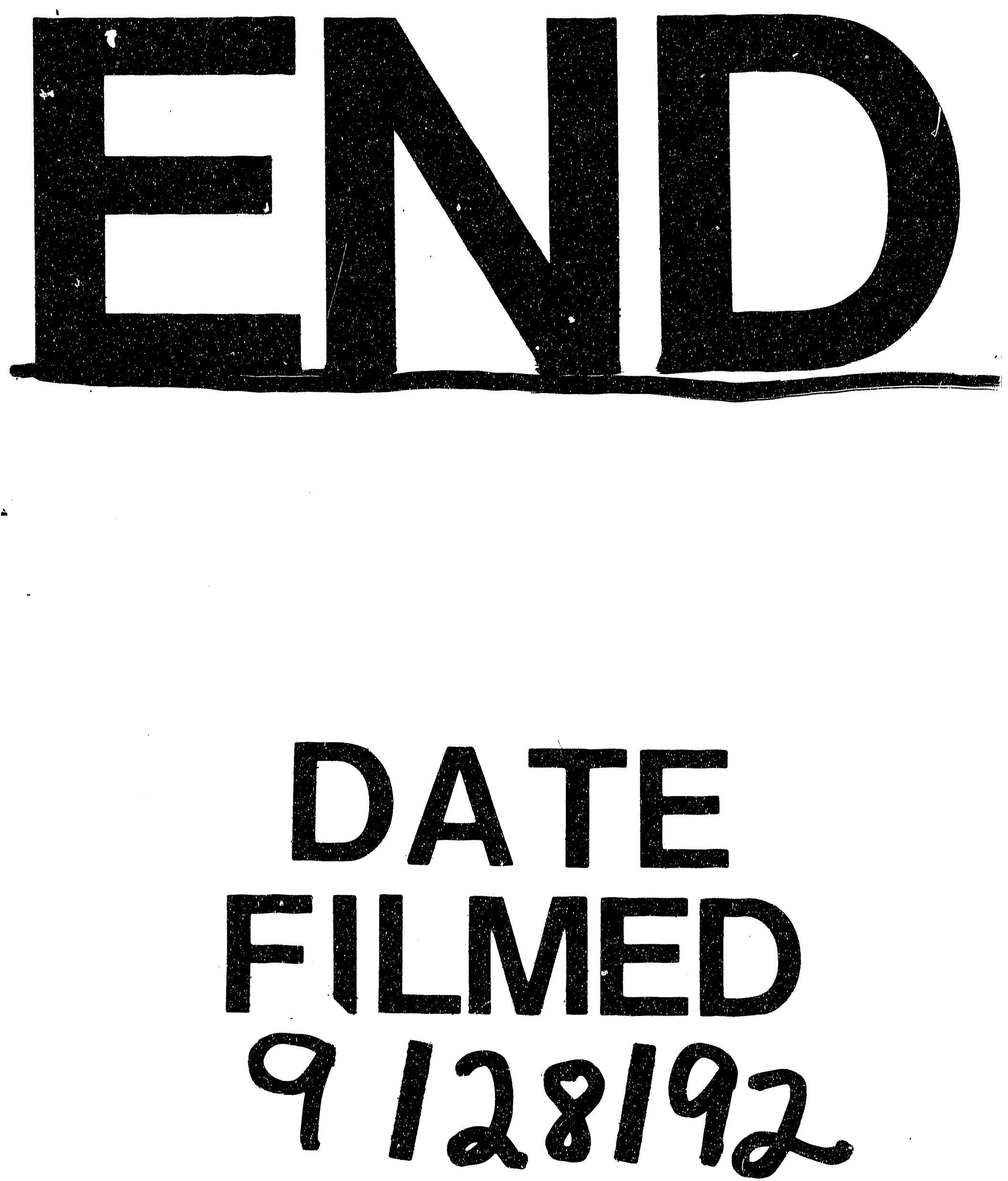
